\title{
A FUNDAÇÁO COMO FORMA DE EMPRESA
}

\author{
MANOEL DE OLIVEIRA FRANCO SOBRINHO \\ Professor Catedrático de Direito Administrativo da \\ Universidade Federal do Paraná.
}

Não obstante as incertezas políticas que são constantes na evolução do processo histórico, não há como não entender o aperfeiçoamento das técnicas administrativas no que diz respeito com a problemática estatal da Administração.

Não basta ao Estado estar organizado politicamente. Precisa muito mais: é necessário que esteja harmonizado com a Administração e dela faça sua expressão de vontade legal, legítima, capaz de atender - serviço público na variada peculiaridade com que se apresenta para satisfação de exigências coletivas.

A isso chamaríamos de racionalização. Tanto o processo histórico, como o jurídico ou o político, fazem uma mesma estrutura organizacional. Harmonizam-se face à realidade e com relação aos fins. A realidade corresponde ao fato. Os fins são aqueles que afetam de momento a sociedade politicamente organizada.

\section{$10^{\circ}$ - REALIDADE E FINS}

Quanto ao fato envolve, nas suas perspectivas, elementos integrativos de ordem social e segurança política. Quanto aos fins aumentam na proporção do complexo das atividades inerentes à safisfação das comunidades, obrigando o Estado à adoção de procedimentos que ampliam a conceituação de serviço público.

Bem dizendo, para o Estado moderno, tudo é serviço público. A própria defesa do homem, como cidadão sujeito de direitos, é função e atribuição do poder estatal através da Administração. Pode ser que sejam diferentes os regimes políticos, mas não são diferentes os métodos específicos de atuação administrativa.

Daí porque, não ser mais possível, distinguir onde a realidade social não distingue, para estabelecer critérios teóricos que afastem 
- elemento público do elemento de direito privado, tornando estanques situações que se complementam ou situações que se completam pela evidência da unidade na ordem jurídica.

Valiosas são, por isso, as contribuições do processo e das leis privadas, civis e comerciais, no sentido da fixação de ceríos problemas que na sua essência são problemas de natureza pública. Ou problemas de fins públicos que se realizam nos limites da esfera privada sem perderem os objetivos de direito público.

\section{$2 .^{\circ}$ - AUTONOMIA APENAS DOUTRINÁRIA}

Não digam que hoje em dia, por força dos sistemas socializantes, pode o Estado separar o interesse público do interesse privado, adotando posições contrastantes com a ordem jurídica integrada. Os que assim teimam esquecem o valor da ordem econômica como base da ordem jurídica e conexa da ordem social.

Aquela marcha do direito para a individualização dos seus quadros normativos não prevalece mais como determinação científica. E válida apenas no domínio da doutrina e das especulações teóricas. Ou é apenas válida para conhecimento de certos fenômenos particulares que somados fazem parte de um todo absoluto e real.

Esse todo é o direito. Não o direito civil ou comercial. Não o direito penal ou processual penal. Não o direito internacional público, privado ou político. Não $\circ$ processual civil ou o direito financeıro. Não o direito constitucional e administrativo. Mas o direito como expressão da conduta humana, política e social.

Quando a Administração, pelo Estado, usa das normas civis, buscando o apoio do Código Civil, nada mais faz que reconhecer meios existentes de efetivação de fins comuns ao próprio direito. Pouco importa, diante do objetivo colimado, a natureza do procedimento ou os peculiares métodos jurídicos adotados.

Enorme é a contribuição do Direito Civil para a formação do Direito Administrativo. Quase todas, senão todas, as instituiçõ̃es de Direito Administrativo, foram buscadas ou senão inspiradas pelo Direito Civil. Somente pelo Estado, como organização política, o direito se torna material e também positivo.

Já vai distante o tempo das longas e fastidiosas disputas entre posições de civilistas e publicistas. Inclusive para dizer aos administratistas que o Direito Administrativo não se deixa fechar nos limites de uma autonomia doutrinária que pretende a separação irreal de pessoas, coisas e fenômenos. 
Houve época em que se falava de um Direito Civil publicizado. Não se fala mais. O que valem são os relacionamentos jurídicos que fazem a espécie da pessoa jurídica. Ou a pessoa jurídica criada pelo Estado como a melhor capaz de absorver determinadas situações à realização de cerio serviço público essencial.

E o caso aqui das fundações, pessoas jurídicas de direito privado, criadas com a finalidade de direito público. E também o exemplo das empresas públicas, pessoas jurídicas de direito privado, organizadas com o intuito manifesto de atendimento de serviços em áreas econômicas de justificado interesse estatal.

\section{3. - - OS INSTRUMENTAIS DE DIREITO PRIVADO}

Importa muito, porém, principalmente para o Direito Administrativo, no que diz com a vontade legal da Adminisiração, saber que ele não desmerece os importantes instrumentos que the são oferecidos pelo Direito Privado, sem forçar, no entanto, distinções de sistema, de procedimento ou de conflito de normas.

Porque essa distinção não existe na realidade do direito, seja público ou privado. O que existem são procedimentos ou processos que mais de perto se coadunam com a problemárica administrativa. E que dão a Administração, elementos jurídicos com que possa cumprir os seus inalienáveis fins de serviço público.

Ninguém discute a imprecisão dos elementos componentes do processo desapropriatório. Como instituto, a desapropriação, tanto poderia pertencer ao Direito Civil como ao Direito Administrativo. Pertence ao Direito Administraftivo ou como tal é aceita, tendo em conta os interesses que levam o Estado a desapropriar.

No ato administrativo, no contrato, o que observamos no fundo: é a característica lógica da norma civil. De igual maneira nas fundações criadas pelo poder público. Ou nas empresas, que nominadas de públicas, como pessoas privadas, dão à Administração, capacidade no atendimento de serviços públicos antes estatais.

Em se tratando da forma jurídica das empresas públicas, impossível não considerar a nafureza atribuída de caráter de pessoa privada, em razão da vontade legislativa cuja importância transcende a hermenêutica. Não cabe ao jurista levantar suspeições interpretativas onde a leì diz ao que vem e o que pretende.

Não é somente uma questão de origem ou de fundamentação legal, legislativa. Trata-se, sobretudo, de uma questão de fało, real 
na estrutura administrativa, indispensável à Administração ativa, quando descentralizada, quando indireta. Principalmente, com respeito ao Estado econômico, ao homem econômico.

Nada há, pois, a admirar, nem a surpreender, com essa nova ou atual tipificação, de fundações e de empresas públicas. Assumem, na verdade, aspectos jurídicos não tradicionais, em virtude da expansão dos fins estatais e da necessidade que o Estado tem para o exato cumprimento de fundamentais exigências econômicas.

Ressalte-se, que depois das sociedades de economia mista, crescem de imporfância as fundações e as empresas públicas. Com apoio nos instrumentais fornecidos pelo Direito Privado quanto à forma e ao processo. Mas com as implicações de fim, de finalidade, que dão conteúdo às pessoas que fazem serviço público.

\section{4. - FUNDAÇÃo e EMPRESA Pública}

Numa tendência que se generaliza, assentada não somente nas práticas administrativas racionais, já se entende poderem as fundações assumir a forma de empresa. Ou as empresas, sem quebra do sistema, assumir a forma de fundação. Isto porque o Estado tem por obrigação procurar os meios mais adequados de administração.

Está no próprio contexto da ordem jurídica essa franquia legal que se exierioriza no serviço público pela determinação das pessoas jurídicas. Sabe o Estado, dentro da própria organização administrativa, o que melhor convém aos propósitos da Administração, no tocante à execução indireta dos serviços públicos.

Não há porque, então, não possa a fundação, trazer na sua estrutura a forma de empresa. E a recíproca também é verdadeira. Motivos não existem, para que as empresas públicas, não se criem como fundações. São ambas sociedades constituidas com respeito ao princípio da legalidade e à disciplina orgânica estatal.

A excessiva privatização da atividade econômica, mercantil e industrial, sempre foi um permanente obstáculo para que o Estado na extensão pudesse devidamente cumprir os seus fins essenciais de vida. Como fato histórico, no direito, o fenômeno é racionalizador e se justifica pela necessidade pública e social.

Do ponto de vista jurídico e organizacional o problema não é tão complexo como parece: a via adotada é a da descentralização administrativa no terreno econômico, utilizada para instrumento na criação de empresas e fundações, com a finalidade, em regime específico, de assegurar o desenvolvimento planificado. 


\section{5. - AS NOVAS FÓRMULAS ADEQUADAS}

As empresas públicas, tal como se apresentam hoje no Direito Administrativo, fazem um fenômeno universal cujos antecedentes correspondem ao período posterior à Segunda Guerra Mundial, e cuja problemática envolve a dimensionada e direta ação empresarial do Estado pela Administração. ( $\left.{ }^{1}\right)$

No sentido próprio dessa problemática estatal, neutralizando a tradição do laissez faire laissez sempre constante, sem quebra do respeito pela liberdade econômica, realizam as empresas públicas como também as fundações, a melhor planificação administrativa em relação à competência descentralizadora do Estado.

Impossível desconhecer que a Administração, ou mesmo o Estado, está comprometida com a segurança da ordem jurídica e pública econômica, impondo-se-Ihe a necessidade da sua presença em todas as fronteiras do desenvolvimento, seja de atividade monopolizadora, de produção industrial ou de reguladora do comércio.

A falta de instituições peculiares ou de regras de direito público harmonizadas com a prática do comércio e o exercício da indústria, levam o Estado a procurar no campo do direito privado as fórmulas adequadas melhor condizentes com a evolução reconhecida daqueles serviços públicos chamados essenciais. $\left({ }^{2}\right)$

O papel relevante das autarquias, marcado na sua importância pela descentralização institucional, onde a orientação de pensamento está forjada em abundanie literatura, não deixa dúvidas com respeito à novos fenômenos integrativos racionalizantes, como o da amplitude descentralizadora e o da desconcentração.

Com as autarquias, exaustivamente estudadas no Brasil, não somente se obteve em certos setores magníficos resultados econômicos e administrativos, como se permitiu que a Administração normalmente alargasse dimensões próprias ao entendimento político do Estado moderno, jurídico e técnico ao mesmo tempo.

Não fosse o serviço público da essência estatal, não surgisse o Estado na sua figuração política como uma síntese, não estivesse a economia condicionada pela influência da racionalização técnica, quem

1) Alfonso Perez Moreno - LA FORMA JURÍDICA DE LAS EMPRESAS PÚBLICAS - Introducion - Sevilla.

2) Ver Urbano Valeo Agundez - LA FUNDACION COMO FORMA DE EMPRESA - Valladolid, 1969. 
sabe as autarquias não oferecessem solução para os problemas vinculados ao desenvolvimento social e econômico. $\left({ }^{3}\right)$

Chegando a vez das fundações, fácil estaria de prever, que a política do Estado voltasse a se interessar pelas empresas, não só tendo em mira a desburocratização das tarefas administrativas, como a urgência de dar ao poder público instrumentos afins e jurídicos, de conformação do Estado com a realidade econômica. $\left({ }^{4}\right)$

\section{6. - AS EMPRESAS PÚBLICAS}

Estranhe-se, apenas, que ainda não hajam para as empresas públicas, na legislação comparada, leis ou estatutos que se apresentem harmônicos como normas gerais e reguladoras. No Brasil, como sabemos, só ultimamente as empresas vem preocupando o poder público, possibilitando a vigência de uma legislação ainda não institucionalizada.

$\mathrm{Na}$ diversidade de motivações, ou por motivo de variedade na atuação empresarial, as formas jurídico-administrativas se confundem em função das circunstâncias. Os critérios jurídicos nem sempre podem ser os mesmos, pois variam face o que constitucionalmente se possa chamar de ordem econômica e social.

Dou razão a ALFONSO PEREZ MORENO:

- "En nuestro dias, la consagración de la técnica planificadora, imponiendo la necesidad de buscar correctivos a las aludidas distorsiones en los órdenes político, económico e jurídico, han determinado el auge de los criterios racionales para dominar el fenómeno, la búsqueda de guias ordenadoras en la elaboración científica operando sobre los datos, ciertamente moldeables, que la realidad histórica de les empresas públicas ofrecon". ${ }^{\circ}$ )

Nada mais certo. De longa data surgem as empresas públicas aparecendo como solução estatizadora. A influência do Estado, sempre presente impôs fisionomia diferente tanto em Portugal, como na

3) Na literatura brasileira: Tito Prates da Fonseca - AUTARQUIAS ADMINISTRATIVAS S. Paulo, 1935; Luis Delgado - AUTARQUIAS - Recife, 1940; Erimá Carneiro - AS AUTARQUIAS E AS SOCIEDADES DE ECONOMIA MISTA - Rio de Janeiro, 1941; A. Nogueira de Sá - DO CONTRÔLE ADMINSTRATIVO SÔBRE AS AUTARQUIAS - Rio de Janeiro, 1952; e Celso Antonio Bandeira de Mello - NATUREZA E REGIME JURídICO DAS AUTARQUIAS - S. Paulo, 1967.

4) Na literatura estrangeira: H. Laufenburger - INTERVENCIÓN DEL ESTADO EN LA VIDA ECONOMICA - Mexico, 1945; Brewer Carias - LAS EMPRESAS PUBLICAS EN EL DERECHO COMPARADO - Caracas, 1967; F. Garrido Falla - ADMINISTRACIÓN INDIRETA DEL ESTADO Y DESCENTRALIZACION FUNCIONAL - Madrid, 1950; e M. Despax - L'ENTREPRISE ET LE DROIT - Paris, 1957.

5) Ver Perez Moreno - ob. cit. - p. 11. 
França ou na Espanha. Na França, a exemplo, por largo tempo, o Estado foi o único empresário no comércio exterior e só por sua iniciativa se criaram as grandes companhias.

A experiência inglesa define os elementos característicos de ordem jurídica e política, marcando por etapas o sentido da evolução das formas de empresa durante o mercantilismo, atribuindo personalidade jurídica às companhias por ações cuja orientação assentava na iniciativa privada. $\left(^{6}\right)$

Precisamente do ensinamento histórico estão se formando as modernas empresas públicas: se por um lado permanecem elas com toda a mecânica inerente aos métodos das organizações de iniciativa privada, por outro lado se apresentam com ampla capacidade para atuar como sujeito de direitos e obrigações públicas.

Tudo depende, no direito interno, do sistema de estruturação da organização administrativa: estruturação que naturalmente envolve o planejamento, a centralização e a capacidade descentralizadora, a descentralização funcional e a desconcentração administrativa, em termos de uniformidade e variedade, e de especialidade.

Realisticamente, o princípio não é outro que este: reconhecer-se no significado histórico e atual a posição da Administração na sua manifesta tendência para outorgar poderes ou delegar funções, no atendimento de uma verdade que procura através de entes menores integrar o poder administrativo, na sua ação direta ou indireta. (7)

Subjetivamente, no caso das empresas e das fundações, está acontecendo isto: um fenômeno-processo em virtude do qual está - Estado transferindo competência variada à órgãos autonômos com uma diminuição de subordinação que se encontra justificada diante dos efeitos periféricos de natureza econômica e social.

Nunca, porém, relegando os pressupostos de coordenação administrativa indispensáveis para atingir a realização prática peculiar à organização estatal e de unidade na atuação de todos os órgãos públicos, pois submetida continua a Administração ao princípio básico de instrumentar-se em técnicas que sirvam à unidade de fins.

6) Perez Moreno - La Evolución de las formas de empresa - ob. cit. ps. 19 e segts.

7) Consultar: Garcia Trevijano - PRINCIPIOS JURÍDICOS DE LA ORGANIZACION ADMINISTRATIVA - Madrid, 1957; Santi Romano - DECENTRAMENTO ADMINISTRATIVO Scritti minori - II - Milano, 1950; Martinez Useros - LA ORGANIZACIÓN Y SUS PRINCIPIOS INSTITUCIONAIS - Murcia, 1960; Valina Velarde - TRANSFERENCIA DE FUNCIONES ADMINISTRATIVAS - Madrid, 1964; Eisenmann - CENTRALIZATION ET DECENTRALISATION - Paris, 1948; e Franchini - LA DELEGAZIONE AMMINISTRATIVA - Milano, 1950. 


\section{7. - ADMINISTRAÇÃO INSTITUCIONAL}

Com justa razão, ENTRENA CUESTA, ao estudar a competência administrativa, não esquece o que chama de relações interorgânicas. São relações de tal natureza que, não só consubstanciam princípios de coordenação, mas também conjunto de funções cuja titularidade se atribui por força do ordenamento jurídico. ${ }^{(8)}$

Convém; outrotanto, lembrar, não esquecendo as formas de sontrole exercidas pelo Estado, que as prerrogativas da Administração se estendem em planos que implicam em obrigações: prerrogativas que não se conflitam com as garantias privadas e nem confundem administrativo com procedimento jurídico-legal.

É de compreender o conteúdo tridimensional do Direito Administrativo moderno, quando

a) numa determinada esfera as suas normas regulam a organização administrativa;

b) numa determinada área estabelece relações interorgânicas entre os entes públicos;

c) num determinado limite relacional jurisdiciona entes públicos e particulares conjugando prerrogativas e garantias. $\left({ }^{9}\right)$

Bem informa ENTRENA CUESTA, esclarecendo com precisão doutrinária, que a administração institucional se constitui quando integra na Administração todos os entes públicos menores de caráter não terriforial, isto é, aqueles entes que se apresentam em forma derivada e com personalidade jurídica definida legalmente. $\left({ }^{10}\right)$

Para o catedráfico de Barcelona, ao que entendemos, incluem-se entre os entes institucionais, ou de administração institucional, as denominadas empresas públicas pelo que dispõem de prerrogativas próprias à Administração e as fundações pelo seu caráter de estrutura e de funcionamento administrativo. (11)

Com as fundações, para exemplo, o que importa, está na personificação de um fim ou de uma função, pouco importando a técnica seguida para criá-las ou seja a técnica fundacional, de vez que que elas dependem da vontade legal criadora, do princípio normativo admitido em lei ou do que o Estado pretende pelo ato instituidor.

8) Rafael Entrena Cuesta - CURSO DE DERECHO ADMINISTRATIVO - La Compefencia Administrativa y las Relaciones Interorganicas - Capítulo V - ps. 175 e segts.

9) Rafael Entrena Cuesta - ob. cit. - p. 61.

10) Entrena Cuesta - La Administracion Institucional - ob. cit. - ps. 337 e segs.

11) Entrena Cuesta - ob. cit. - ps. 338/9. 
Não devemos, portanto, levantar dúvidas, onde dúvidas não existem. Pelas determinantes da criação legal, pelo caráter instifucional e regime jurídico, as fundações como as empresas públicas inscrevem-se como organismos autônomos ou como entes menores de natureza administrativa, sob a tutela do Estado.

Tudo reside no motivo determinante da criação que tende para o cumprimento de um fim de serviço público: quanto ao carárer institucional nas empresas públicas e fundações afirma-se não só pelo cumprimento das finalidades específicas, mas pelo desejo do Estado em descongestionar a Administração central.

\section{$8^{\circ}$ - AS FUNDAÇÕES}

Considere-se que, depois das autarquias, passada a febre das sociedades mistas, apareceram as fundações na área da Administração e do Direito Administrativo, como o fato mais notável de descentralização ou desconcentração, como a iniciativa legal mais apropriada ao arendimento de certas obrigações estatais e públicas.

Correspondendo as fundações, as empresas públicas se impuseram na esfera administrativa estatal, num mesmo plano igual de atividade indireta, atuando ou não num regime de monopólio, gestionando ou não um serviço público em sentido estrito, como resultado de processo racionalizante e nacionalizador. ${ }^{\left({ }^{12}\right)}$

Separados os fins, discriminada a finalidade, adotado o processo privado de personificação jurídica, a posição das empresas públicas no quadro da Administraçâo institucional é a mesma, irrelevantes que se tornam as formas e os tipos casuísticos, ou as correlações com a organização administrativa.

Na recente evolução planejada diante das exigências do desenvolvimento econômico e social, verifica-se pelo sentido e alcance do fim público, que a realidade do ordenamento jurídico, apaziguou tendências diversas em favor de condições cuja tipicidade não obrigam o Direito Administrativo a qualquer opção.

A significação ontológica da forma jurídica adotada para as fundações e empresas não implica com a doutrina clássica, pois a perspectiva o que visa outra coisa não é que a valorização do sistema jurídico privado na gestão de setores públicos representativos de problemas que afetam a competência do Estado.

12) Garrido Fala - apud Perez Moreno - ob. cit. - p. 33. 
Alguns pontos são comuns, nas empresas públicas, à atividade concreta das fundações. PEREZ MORENO, enumera três que aceitamos:

a) insuficiência da iniciariva privada, incapaz de corresponder a fins de caráter geral para as diversas modalidades fundacionais e empresariais

b) a conveniência de se impedir ou combater as práticas restritivas ao exercício da competência estatal;

c) imperativos de defesa dos altos interesses nacionais no tocante à exploração de novas e velhas fontes econômicas. $\left({ }^{13}\right)$

No que respeita às fundações, com o critério de competência técnica reforçando o critério da competência jurídica, a intervenção esiatal pelo ato de criação traz no seu bojo como consequência do processo privado a figuração de um órgão ou organismo-ente coordenado aos órgãos centrais de governo e de administração.

No exercício de uma função, de gestão de serviço público, vigora o princípio da discricionaridade organizacional dentro da ordem jurídica, segundo o qual o Estado pela Adminisiração no uso da sua autoridade legal pode outorgar-se o papel de interventor para assistir interesses sociais, assistenciais ou educacionais.

Mudada a equação, quanto ao fim, da atividade-forma-jurídica, as fundações passam a assemelhar-se às empresas públicas, preponderando sempre a autonomização indispensável à personalização do ente administrativo, e tendo no substrato personificado as exigências que revestem a pessoa jurídica na sua extensão legal.

Com as fundações o fenômeno que acontece, é este: a Administração criando-as, personifica entes, como necessidade de obedecer o princípio da divisão do trabalho administrativo para a realização de fins que justificam os meios, sem com isso violentar a ordem jurídica ou desmerecer as tarefas que lhe devem ser cometidas.

Nada há demais que a Administração recorra à personificação jurídica e privada através dos instrumentos de direito privado, eis que as formas sempre novas que possa adotar integram-se à organização geral do Estado acudindo situações e tarefas que a rigor vinculam-se à setores diretamente afetados pelo interesse coletivo.

Pelo princípio da divisão do trabalho administrativo, que permite ao Estado ampliar as suas áreas de ação administrativa, jamais será aconselhável a concentração de tarefas públicas de fins de ser-

13) Ver LA FORMA JURídICA DAS EMPRESAS PUBLICAS - ps. 51/2. 
viço público, quando a Administração pode impor normalmente o recurso da necessária e peculiar personalidade jurídica.

\section{9. - DETERMINAÇÃO DO CRITÉRIO INSTITUCIONAL}

A administração pública, respeitando a organização política estatal, em sentido amplo e de sistema orgânico, está naturalmente integrada por uma pluralidade de entes públicos: o Estado, pelo óbvio, em primeiro lugar, e, em segundo lugar, a série de entes que fazem a denominada Administração indireta, entes esses que possuem caráter territorial e outras vezes caráter institucional. $\left({ }^{14}\right)$

As funções públicas que se distribuem entre os entes administrativos conforme critérios de ordem e de eficácia, de meio e de fim, de necessidade e de serviço, cada uma dessas unidades constituindo um organismo peculiar, ou um órgão administrativo, dão como resultado a organização geral administrativa, não só pelo conjunto de relações jurídicas recíprocas, mas pela hierarquia, coordenação e subordinação.

Acompanhando o pensamento de ENTRENA CUESTA, estamos concórdes que o órgão com elementos pessoais e materiais adestritos à realização de um fim, forma uma instituição: essa característica institucional de órgãos administrativos, conforme a atribuição de personalidade legal, face às relações que só podem existir entre sujeitos de direito, explica-se pela conduta da Administração quanto às obrigações estatais. ${ }^{(15)}$

Apreende-se, portanto, que é neste plano que se colocam as fundações e as empresas públicas, estimando-se:

a) o limite da competência administrativa;

b) a titularidade para a função específica;

c) a esfera própria de atuação legal e jurídica;

d) a categoria dos direitos recebidos;

e) o caráier dos deveres assumidos;

f) a consecução do interesse público.

Em consequência dessa postura, da existência da pluralidade de entes administrativos integrando a Administração, do princípio que leva o Estado à categorizar pessoas jurídicas, é certo que as fundações

14) Rafael Entrena Cuesta - Caracteres y Contenido de la Administración Institucional ob. cit. - ps. 338 e segts.

15) Ver CURSO DE DERECHO ADMINISTRATIVO - cit. - ps. 346 e segts. 
como as empresas públicas ostentam além de competência subjetiva também competência orgânica.

Uma e outra competência, a orgânica e a subjetiva, estão nas funções legitimamente exercitadas: há, por assim dizer, um direito subjetivo ao exercício dessas funções; há, por condição do ordenamento jurídico, órgãos com atributos de capacidade preferencial no sentido de que são titulares de direitos e de obrigações.

Considerando a importância da competência administrativa na organização e atividade dos entes públicos ou criados pelo poder público, ressalte-se que as regras adotadas seguem uma determinação de critério institucional:

a) quando implicam com a adoção de formas específicas, isto é, indicativas do modo de como possam ser exercitadas;

b) quando a especificação constitui-se em atributo do órgão, isto é, resulta de princípios concretos reguladores do pretendido serviço público.

Destaque-se, outrossim, a influência da coordenação administrativa nas diferentes técnicas de atuação estatal, que não escapa:

a) da hierarquização como estrutura;

b) da fiscalização e da tutela legal;

c) da subordinação que reduz à unidade a multiplicidade dos entes administrativos.

Através de relações de subordinação, porque não dizer de supremacia, pela hierarquização passam a dispor os órgãos superiores de faculdades de controle da conduta dos órgãos inferiores, mediante uma ordenação sisłematizada que encontra guarida na ordem jurídica e nos princípios positivos de natureza legal.

Nas fundações, como nas empresas públicas, dirigir, inspecionar, ordenar e tutelar, é condição imperativa da organização administrativa: jamais a fiscalização pela tutela, na repartição do trabalho administrativo, infringe a autonomia da pessoa jurídica ou restringe a delegação concedida para a eficácia do serviço público.

\section{$10 .^{\circ}$ - $O$ CONTROLE OU TUTELA}

Está claro, que o controle, ou a tutela, não se presume, porque está expressamente consagrado no direito positivo. E, como supõe, uma exceção à autonomia do ente descentralizado, deve ser aceito restritivamente para consagrar a Administração na unidade da sua capacidade geral de autodeterminação. 
Assim é com as autarquias. Com as fundações e as empresas públicas, num sentido de limitação em função de atividade permitida. A causa da tutela administrativa reside na necessidade de não se quebrar a unidade na afuação de quantos entes persigam os fins públicos, fins que são inerentes à atividade estatal. $\left({ }^{16}\right)$

Para RAFAEL ENTRENA CUESTA, entre a hierarquia e a polícia administrativa, está o conteúdo da tutela adminisłrativa integrada pelas faculdades de controle outorgadas com caráter limitado pelo direito positivo ao ente cujo fim é o serviço público, não se admitindo, porém, livremente, que o sujeito tutelante possa ditar ordens ao sujeito tutelado. $\left({ }^{17}\right)$

Prevalece, como no caso das fundações, o princípio criador que se transforma em orientação estatutária. Ou no caso das empresas, onde a tutela visa lograr à falada unidade de atuação, sem o que impossível seria estabelecer-se a legalidade e a oporiunidade de atos passíveis de controle jurisdicional.

Afirmando-se, como pondera PEREZ MORENO, que a Administração personifica "organizaciones" como forma articuladora do princípio de divisão do trabalho, ou que a concentração das tarefas assumidas pela Administração impõem necessidade de distribuição, nada mais normal que a exigência do controle ou da tutela administrativa. $\left({ }^{18}\right)$

$\mathrm{Na}$ Administração indireta, o papel atual das fundações, como - papel que representam as empresas públicas, ambas levadas à formação através do recurso da personalidade jurídica e privada, corresponde pelas prerrogativas outorgadas a um mesmo objeto prático: servirem o Estado como compartimento da Administração geral, de atuarem em nome do Estado em áreas públicas diretamente afetadas.

$\mathrm{Na}$ expressão do professor de Sevilha,

- "la personificación de esos entes constituye, en definitiva, la creación de nuevas formas jurídicas, de nuevos sujetos para los que se elabora un Derecho especial". $\left.{ }^{19}\right)$

Mas de novas formas jurídicas, com a adoção de uma forma jurídica de direito privado, por onde não pretende a Administração fugir da aplicação do Direito geral normativo desde quando para os esquemas clássicos de serviço público, submete fundações e empresas ao direiło privado para gestionar fins públicos.

16) R. E. Cuesta - ob. cit. - p. 153.

17) idem - ob. cit. - p. 152.

18) Ver LA FORMA JURIDICA... - cit. - p. 71.

19) Perez Moreno - ob. cit. - p. 74. 
Estamos com GARRIDO FALLA quando define a descentralização no seu rigoroso sentido dinâmico como a transferência de funções ou competências dos órgãos estatais às demais pessoas jurídicas públicas, mas não só transferência às pessoas públicas como as privadas de sua criação mediante controle ou tutela. $\left({ }^{20}\right)$

A mesma indagação que vale para as empresas públicas é válida para as fundações: estão elas, fundações e empresas, enquadradas à organização estatal? A resposta só pode ser afirmativa, pois não há polemica lógica quando entes desceníralizados ficam submetidos à tutela administrativa por formação coativa.

Concordar, não obstante, com GARRIDO FALLA, para afirmar que as empresas públicas não estão enquadradas na administração estatal mas que fazem parte da administração pública, não é o caminho mais adequado para a solução do problema em relação ao que o Estado pretende realizar por meio de pessoas privadas. $\left({ }^{21}\right)$

Em falando de descentralização funcional, observando-se a Administração no seu aspecto intervencionista, ou apontando como realidade o fenômeno da integração orgânica do Estado, não há como poder distingui-la da descentralização por serviços, tal a semelhança de propósitos em face da relação jurídica.

Basta aqui, o controle ou tutela, para aclarar-se a natureza da relação entre fundações e empresas como entes descentralizados e a Administração: qualificar essa relação não é trabalho da doutrina e nem da crítica doutrinária, mas do direito por motivo de normas gerais e por consequência estatutárias.

\section{$110^{\circ}$ - A FUNDAÇÃO-EMPRESA}

A tese aceitável, que ainda está no domínio da doutrina, pertence, no momento, a URBANO VALERO AGUNDEZ, com a supervisão de JOSÉ GIRON TENA, ambos da Universidade de Valladolid, na Espanha. ${ }^{(22)}$

E plausível a existência da fundação-empresa? Pode a fundação surgir como uma nova forma de empresa? Será possível uma empresa ter caráter fundacional? Em razão da estrutura e do regime jurídico poder-se-á conjugar numa mesma pessoa duas manifestações jurídicas

20) Ver ADMINISTRACIÓN INDIRECTA DEL ESTADO Y DESCENTRALIZACIÓN FUNCIONAL Madrid, 1950; Valina Velardo - TRANSFERÊNCIA DE FUNCIONES ADMINISTRATIVAS Madrid, 1964.

21) Fernando Garrido Falla - LA DESCENTRALIZACION ADMINISTRATIVA - ps. 28/9.

22) Ver LA FUNDACION COMO FORMA DE EMPRESA - Valladolid, 1969. 
diferenciadas? No interesse público permite-se ao Estado adotar regime comum contrariando disposições de procedimento legal?

Como pode a fundação ser utilizada como empresa? Mesmo havendo funções conexas como harmonizar a idéia de fundação com a idéia de empresa? Já não existem fundações que agem com fins de empresa? A organização de uma fundação como empresa pública deve admitir configuração própria fora do princípio estatutário? E a empresa pública sob forma fundacional conflita-se com a natureza das instituições?

As indagações, no que não escapam do pensamento jurídico realista, merecem inteira concordância frente à realidade do Estado moderno como organização política e administrativa. Não se concebe, hoje em dia, o poder público não interessado pelas novas técnicas de atuação no campo do direito, quer público ou quer privado. $O$ que importa é que o serviço público seja prestado na extensão das necessidades coletivas.

Se o veículo da prestação forem as fundações, nada mais justo que adotá-las na dimensão de uma racional descentralização funcional. Caso o veículo aconselhável sejam as empresas, certo que se faça delas expressão dos serviços econômicos que o Estado tem por obrigação prestar. Havendo, no entanto, conveniência de uma forma conexa que $\circ$ processo novo ganhe estrutura no contexto do regime administrativo.

Ao Estado, pela Administração, é que não se permite o alheiamento quanto à possibilidade apresentada de acolher novas fórmulas indicadas pela prática e que melhor forem condizentes com a execução dos serviços públicos. Para a problemática estatal importantes serão sempre os instrumentais administrativos que possam adequar os problemas às soluções, os métodos às resultantes de fins necessariamente públicos.

Ademais, mesmo que não haja orientação predominante, razão alguma se pode opor à possibilidade de constituição de fundaçõesempresas. A organização de uma fundação com forma de empresa e conteúdo empresarial e a inclusão dela como organismo da Administração pública, em coisa alguma poderá alterar a influêncỉa do Estado quando no exercício pleno das suas prerrogativas primaciais e de supremacia.

Substancialmente não se modifica, nem pelo processo jurídico, a natureza da instituição. A arividade executiva que se torna estatal nas empresas e fundações, resulta de funções anteriormente outorgadas 
por ato de autoridade competente encarregada na ordem jurídica de promover satisfações coletivas econômicas e sociais. Quanto à instituição mantem-se na pureza da sua forma, apesar da evolução dos fatos públicos.

\section{$12 .^{\circ}$ - A SITUAÇÃO NO DIREITO POSITIVO}

$\mathrm{Na}$ verdade dissemelhanças essenciais não existem em questão formal entre as fundações criadas pelo Estado e as empresas públicas estatais. São simplesmente pessoas administrativas funcionalmente descentralizadas na órbita da Administração instifucional. Aparecem e se criam, na ordem jurídica administrativa, em atendimento de um serviço que é público, do Estado, e, portanto, do interesse da Administração.

No direito positivo a situação sequer se altera em relação à orientação tomada pelo Direito Administrativo. Jamais houve segiedo, nem conflito doutrinário, com respeito à posição das autarquias. Oposição não houve, entre os doutrinadores, quanto à participação das entidades autárquicas no quadro da Administração geral. Sobretudo, as leis civis e os Códigos, sentiram-se respeitadas e estimuladas. $\left({ }^{23}\right)$

No entanto, antes de formalizadas legalmente, as autarquias inexistiam para o direito positivo. Como pessoas jurídicas, ouvidos os códigos de leis civis, não tinham lugar própria na tradicional classificação de pessoas. Bastou a manifestação da vontade estatal para que as autarquias viessem a ocupar posição de destaque na Administração, atendidas de plano que foram certas áreas de interesse público.

Irrelevante, portanio, a controvérsia, no que diz com as empresas públicas e as fundações. Pelas possibilidades institucionais a Administração insuficientemente aparelhada, não está impedida de amparar-se nos institutos privados. Ao contrário, tem neles elementos jurídicos com que cumprir obrigações inalienáveis, desde que mantenha - Estado a sua tônica de poder político com responsabilidades administrativas.

Não prevalecem com as fundações as dúvidas que incidiram sobre a conceituação e a posição das autarquias. Possuem os entes fundacionais características jurídicas marcadamente acentuadas no direito positivo. Bastam-se pelos elementos integrativos que não isolam

23) No Brasil já vai longo o processo de consagração das autarquias como pessoas jurídicas públicas integradas na Administração estatal. Três importantes autores fazem história na literatura brasileira: Tito Prates da Fonseca - AUTARQUIAS ADMINISTRATIVAS - S. Paulo, 1935; Celso Antônio Bandeira de Mello - NATUREZA E REGIME JURIDICO DAS AUTARQUIAS - S. Paulo, 1967; e Alberto B. Cotrim Neto - DIREITO ADMINISTRATIVO DA AUTARQUIA - Rio, 1960. 
- Estado da tutela legal. Elementos que são componentes e de conteúdo jurídico, seja qual seja o fim da promoção fundacional.

De maneira igual, com as empresas públicas, adotou a Admınistração, o comportamento aconselhado pelo direifo positivo. Recorre às empresas, respeitando a ordem jurídica, objetivando indiretamente determinada prestação de serviços. Sem contudo, precisar violentar regras de procedimento aconselháveis à adequação do problema. Com isso, não excepcionalizada, mas integra buscando a colaboração do direito privado.

Está bastante clara a afirmação esclarecedora de URBANO VALE RO AGUNDEZ:

- "en la actual situación de nuestro Derecho positivo, a falła de una reglamentación legal de la fundación como forma de empresa, todas las reservas seriam en ella reservas estatutarias o reservas facultativas". $\left.{ }^{24}\right)$

$\mathrm{Na}$ vontade instituidora ou criadora não intervem o direito positivo e nem as regras recomendadas de procedimento legal. Cabe ao fundador, ou criador, no caso o Estado, estabelecer as motivações do ato, procurando as formas mais suscetíveis de entrosamento do fim público à Administração. Na declaração da vontade afigura-se com precisão a harmonia entre a norma privada e o interesse público.

Para URBANO AGUNDEZ,

- "no parece haber motivo alguno para dudar do ello, toda vez que al fundador le corresponde establecer la medida en que los beneficios fundacionales, también en el caso da fundación-empresa, deben ser distribuidos entre sus destinatários o aplicados, en general, a los fines fundacionales". $\left({ }^{25}\right)$

Conclue-se, portanto, que nem do ponto de vista econômico e nem do ponto de vista jurídico, hajam obstáculos à criação da fundação-empresa. As reservas aconselháveis seriam estafutárias quanto aos meios e com relação aos fins. $O$ exame da conveniência fica na alçada administrativa. O problema da possibilidade pertence à Admi nistração quando no exercício das suas faculdades discricionárias.

\section{3. - - ADMINISTRAÇÃO E ORGANISMOS AUTONOMOS}

Já o Direito Administrativo esgotou uma farta literatura de como na prática institucional e organizacional comportam-se os organismos

24) Ver LA FUNDACIÓN... - cit. - p. 322.

25) Urbano Valero Agundez - ob. cit. - p. 322. 
autonomos. Surgem eles pela necessidade de várias imposições: as políticas, as sociais, as assistenciais, as econômicas, descentralizando ou desconcentrando as funções estatais.

Não existem, porém, no direito comparado, e nem nos direitos nacionais, princípios gerais reguladores da estrutura administrativa dos organismos autônomos. Princípios que passem a obrigatórios para a formação de entidades cuja finalidade correspondam à serviços públicos ou de interesse público.

Preferível a expressão prerrogativas da Administração para com ela dar sentido às iniciativas que se tomam em todas as dimensões da atividade estatal: na verdade são prerrogativas de quem inclusive tutela o direito na sua aplicação material e responde pelos proilemas de uma sociedade política em desenvolvimento.

Apesar da descentralização, os organismos autônomos, são entidades afluentes em face da Administração. Para os países desenvolvidos, a meta outra não será que aquela favorável à desconcentração do trabalho administrativo, num Estado de direito que possibilite ampla distribuição de funções e atribuições específicas.

Nos países em desenvolvimento, a importância das novas técnicas distribuídas de procedimento é ainda maior, considerando-se que - Estado não é apenas uma organização de polícia e de negócios fiscais. Como corpo político de uma nação, o Estado é um complexo orgânico, sofrendo transformações históricas de regime e de sistema.

Deve, por isso, como unidade e pelos seus órgãos, de indole legislativa, jurisdicional e executiva, em razão da heterogeneidade de funções que caracterizam a Adminisiração, caminhar dando formas às diversas manifestações da sociedade política, sem o que não poderá atender $\circ$ que exigem os acontecimentos sociais.

Não se trata, hoje em dia, de submeter, obviamente, a Administração à lei, ao direito e, por conseguinte, à defesa da liberdade, no dizer de JEAN RIVERO. $\left({ }^{26}\right)$ Como organização superior, complexa e composta, o Estado, está orientado por distintos ordenamentos jurídicos que não fogem as transformações do tempo histórico.

Nos organismos autônomos encontra o Estado os meios jurídicos de expansão que correspondem à universalidade da problemárica administrativa, cumprindo-se assim mediante postulados de direito comum o público, de vez que o Direito Administrativo tornou-se fruto de duas revoluções do século XIX: a política e a técnica. ${ }^{(27)}$

26) Ver L'ÉTAT MODERNE PEUT'IL ÉTRE ENCORE UN ÉTAT DE DROIT? - Liége, 1957.

27) Jean Rivero - COURS DE DROIT ADMINISTRATIF COMPARÉ - ps. 27 e segts. 
Vigora dest'arte, na aplicabilidade e na prática, o princípio da hierarquia normativa, sobrefudo organizacional, escalonando a atuação pública estatal em termos de realidade geográfica e institucional, unificando na variedade e planificando nas mais distintas relaçŏes de autonomia e subordinação.

Em concordância, pois, com o ordenamento jurídico, os organismos se integram na Administração nos limites da competência concedida. Seja a competência de atribuição genérica quanto ao fim ou especifica, personaliza e titula pela vontade esiatal serviços admınıstrativos institucionalizados.

\section{4..$^{\circ}$ - A MODALIDADE FUNDAÇÃO NA EMPRESA}

A fisionomia de qualquer figura jurídica, principalmente as nascidas do direito positivo, define-se pela expressão técnica ou por um complexo de elementos técnicos que possibilitam atuação no ordenamento jurídico estabelecido. O fim fundacional, sendo o interesse público, não impede objetivo de natureza econômica.

A função do fim fundacional no regime jurídico das fundações, não obstante a estrutura ou o funcionamento delas, não se conflita com a idéia de empresa, desde que o patrimônio esteja destinado à efetivação de resultantes econômicas e diretamente compromet:do com o que pretendeu o fundador no ato de instituição.

Está visto, que o conceito atual de fundação, não se confunde com o conceito tradicional, superadas que estão aquelas finalidades clássicas em viriude da expansão do interesse público em áreas anteriormente entregues à responsabilidade da iniciativa particular, onde - Estado apenas fiscalizava e não tutelava.

Atualmente, e os exemplos são tipicamente fundacionais, as fundações não se classificam tão somente como culturais, carifativas, beneficientes ou religiosas. Vão muito mais além com a intervenção direta do poder público quando o Estado procura atender certos setores criando como fundador entes que prestam serviços públicos.

Nada há demais no fenômeno. Facilmente é explicável diante de certos problemas que exigem solução jurídica adequada. É para - poder público uma questão de necessidade promover a criação de organismos supletivos encarregados de uma finalidade e com bens e direitos que se incorporam ao patrimônio fundacional.

O relacionamento, portanto, diz respeito ao fim, à finalidade, ao que pretende o. Estado quando se faz fundador de uma fundação. Em 
princípio qualquer classe de bens podem constituir o elemento patrimonial de uma fundação, sem com isso perder o Estado em subs tância aquilo que pretende com fim público ou administrativo.

Em qualquer caso onde haja a interferência crỉadora do poder público, a afetação dos bens a um fim predestinado, resulta de uma obrigação relacional, de um direito real ou de uma vontade protegida pelo direito, vontade essa vinculada ao ato instituidor da pessoa jurídica, seja a pessoa uma fundação ou uma empresa pública.

Simplistamente analisando, tendo em conta a concreta manifestação da vontade estatal, identifica-se o fim institucional tanto nas fundações como nas empresas, em razão do processo que se aplica ao fato, em virtude da afetação de bens que motivaram a criação de um novo sujeito jurídico e personalizado.

E lógico que, se com a forma jurídica de empresa se pretende criar um sujeito de atuação econômica, dotado de uma organização jurídica especial para o cumprimento da dita atividade, nada impede que a pessoa seja uma fundação com personalidade peculiar e característica orientada para fins empresariais.

Para VALERO AGUNDEZ, a fundação-empresa, é uma fundação: uma fundação com base na titularidade jurídica imediata sobre a em. presa, em virtude de uma exigência institucional derivada da força normativa dos estatutos, da vontade do fundador e da característica atividade econômica que traz como fim. $\left({ }^{28}\right)$

\section{5. - A QUESTÃO DA PERSONALIDADE JURÍDICA}

Por paradoxal que seja, a questão da personalidade jurídica, já não é mais uma questão de alta indagação: no comum das vezes, o procedimento estatal é típico do direito público, orientando-se bor princípios não de opção estatal quanto ao regime, mas de potestade pública que dá à Administração capacidade para soluções buscadas no direito privado.

Qual o regime jurídico das fundações, no Brasil e no direito comparado? Qual o regime jurídico das empresas públicas no Direito Administrativo, brasileiro e comparado? Ao que parece não existem distinções que possam preocupar a posição do pensamento doutrinário.

A intervenção do Estado na ordem econômica e social, é o traço de união na sistemática entre as fundações e as empresas. Levada à desempenhar atividades indiretas de natureza diversificada, a Admi-

28) Ver LA FUNDACION... - Diversas Manifestaciones de la Fundación - ob. cit. - p. 129. 
nistração adotando personalidade jurídica de direito privado apenas tende para conveniências de política administrativa em face da organização estatal. ${ }^{29}$ )

Cabe ao Estado, na individualização, ou personificação de serviços essenciais, decidir quanto à forma e o conteúdo da outorga ou delegação e na decisão determinar o procedimento e o fim: autarquias, sociedades de economia mista, empresas públicas e fundações, serão os veículos mais apropriados para uma efetiva atuação indireta do poder público.

Encontram-se, assim, harmoniosamente, dentro da esfera do Direito Administrativo, a excelência de dois regimes jurídicos: o regime jurídico público e o regime jurídico privado, ambos os regimes marcando prerrogativas e sujeições no melhor proveito do serviço públičo indireto. $\left({ }^{30}\right)$

O regime jurídico privado das empresas públicas, como a personalização jurídica das fundações, decorrem da própria nafureza das pessoas privadas que são: a presença do Estado, pela Administração, no caso das empresas, objetiva fins públicos, isto é, stałus legal de onde ressaltam-se caractéres típicos e constitutivos específicos. $\left.{ }^{31}\right)$

Em resumo: quer as empresas públicas, quer as fundações, atendendo à peculiar personalidade jurídica, constituem-se através de patrimônio estatal, personalizado sob a forma de pessoa de direito privado, criadas por lei para gerir inieresses públicos afetados a fins econômicos, sociais, assistenciais ou educacicionais, sempre um serviço público.

Vale, portanto, o fim de interesse ou de serviço público. Fim que fica submetido a regime jurídico que melhor convier ao Estado dentro da ordem jurídica estabelecida. Fim personalizado juridicamente dentro de esquema privatistico que não desmerece a Administração nas suas prerrogativas públicas e de atuação na ordem pública geral.

29) No direito positivo brasileiro ambas as entidades estão definidas no Decreto-Lei n. 200 e no Decreto-Lei n. 900 . Explorar atividades econômicas e outras atividades configurando pessoas jurídicas que a lei prevê, não é mais mistério algum para a doutrina em razão da lei. Adotar o regime jurídico está na vontade do Estado. Trata-se aqui de descentralizar para efeito de colaboração. No fundo está o interesse público.

30) Como é obvio, por exemplo, a empresa, recebe o nome de pública, quando é criada e mantida pelo Estado (Ernest Forsthoff - TRATADO DE DERECHO ADMINISTRATIVO p. 662).

31) Ver: Nicola Balog - A ORGANIZAÇÃO ADMINISTRATIVA DAS EMPRESAS PÚBLICAS RDA - 88/41; Jean Riv́ero - DROIT ADMINISTRATIF - ps.: 424/5; Natalia Gail - AS EMPRESAS ESTATAIS NA FRANÇA, ITÁLIA E POLONIA - RDA - 70/43; Ernest Forsthoff ob. cit. - p. 662 . 


\section{$16 .^{\circ}$ - METODOLOGIA DO DESENVOLVIMENTO}

Tornou-se convincente que o mais importante para o Estado moderno é o processo e não a forma jurídica somente: as técnicas administrativas podem e devem variar sem violentação da ordem juridica, ficando a Administração com a responsabilidade de encontrar a meIhor solução para os seus problemas específicos.

Uma organização ou uma entidade descentralizada é muito mais do que uma simples pessoa jurídica: precisam os entes da Administração indireta atender as necessidades humanas em harmonia com as metas administrativas, num comportamento afeito às institu:ções que evoluem em razão da dinâmica social que impõe mudançăs de estrutura.

Um bom programa administrativo não pode ser cristalizado, porque deve ser orientado segundo as necessidades específicas inicdiatas do Estado. Qualquer estrutura rígida acabará totalmente inadequada às manifestações voletivas estatais imperativas, de vez que a Administração não esłá alheia aos impulsos resultantes do desenvolvimento social e econômico.

Exatamente para atender as necessidades públicas é que a Administração se torna flexível: aperfeiçoar, portanto, os métodos, tornando-os capazes de atender o desenvolvimento, outra coisa não é que colocar o Estado à altura dos problemas que exigem aparelhariento administrativo próprio.

Já num Anteprojeto de Lei Orgânica do Sistema Administrat'vo Federal brasileiro, com respeito aos serviços estatais dependentes da Administração direta, antecipava-se com inteligência no parágraio $1 .^{\circ}$ do seu artigo $7 .^{\circ}$ :

- "equiparam-se à empresa pública, para os efeitos desta lei, as fundações instituidas com recursos exclusivos da União, quaisquer que sejam as suas finalidades". $\left({ }^{32}\right)$

Não há como não saber que as atividades econômicas diferem intrinsecamente em complexidade. Quanto à eficácia da Administração depende, em grande parte, das leis e instituições que se inte'yram no quadro do regime jurídico, e que determinam a existência de pessoas e de entidades administrativas capazes pelos novos métodos de dar sentido ao desenvolvimento.

Equiparar, portanto, as empresas públicas às fundações, objetivando a dinâmica do desenvolvimento administrativo, chama-se ajus-

32) Homero Senna e Clovis Zobaran Monteiro - FUNDAÇÕES... - p. 73. 
tar conhecimentos técnicos às imposições do processo tecnológico, ampliando, assim, a capacidade estatal, em têrmos de governo integrado na reformulação de processos que desconcentrem pela divisão o trabalho da Administração.

Não resta dúvida que em administração os objetivos, "a poítica de ação e os procedimentos são sempre relacionados de modo dinâmico e tendem a se tornar focalizados no momento de ação e ciecisão administrativas: desde que as entidades são um todo e suas virtes inter-relacionadas, a administração tem de ser encarada como um processo global". $\left.{ }^{(33}\right)$

Dois corolários são exałos na lição de MARCELLO CAETANO:

$10^{\circ}$ - A personalidade é um produto do ordenamento jurídico, concessão exclusiva do Estado. Nunca os homens, com os seus contratos e as suas organizações voluntárias, poderão fazer nascer uma pessoa coletiva, sendo sempre necessária a intervenção do Estado, através dos seus órgãos e aułoridades. $O$ reconhecimento é o fator constitutivo da personalidade jurídica.

$2 .^{\circ}$ - Sendo a atribuição da personalidade apenas a concessão de capacidade jurídica, pode esta ser mais ou menos ampla, limitar-se ao direito privado ou esłender-se também à esfera do direito público. Mais: quem determina tal capacidade é sempre a ordem jurídica. árbiIro de conferi-la em geral ou sob forma limiłada, fragmentária oy. parcial. $\left({ }^{34}\right)$

\section{$17 .^{\circ}$ - SUBSTRATO CERTO NA ORDEM JURÍDICA}

Ninguém mais contesta o Estado na sua plena capacidade interventora ou de intervenção no domínio econômico e social. A Administração deve ficar com liberdade para decidir. Nas fundações e nas empresas, ou mesmo na fundação-emprêsa, depende o patrimônio afetado de quem reconhece a pessoa jurídica e das regras comuns recomendadas pela experiência.

Não se trata, em razão do poder discricionário, de saber ou discutir qual a solução preferível. O reconhecimento específico é taxativo e normativo desde quando a lei confere ao ato instituidor o efeito formal da outorga da personalidade. O ato de instituição é, pois, assim, a manifestação unilateral da vontade estatal em face do interesse público.

33). Harleigh B. Trecker - NOVAS PERSPECTIVAS DE ADMINISTRAÇÃO - p. 35.

34). Caetano fundamentado em Ferrara - DAS FUNDAÇÕES - ps. 53/4. 
É pacífico que 0 ato de instituição tem caráter próprio e específico, constituindo uma categoria jurídica peculiar de negócio jurídico unilateral. $\mathrm{Na}$ verdade, não há dificuldade alguma, em conceber-se o Estado na sua qualidade de poder público provendo uma necessidade pública, mas com o ânimo de cumprir obrigações que line são essenciais e imperativas.

Nada mais simples do que aceitar a personalidade como uma qualidade jurídica com substrato certo na ordem jurídica: não há, portanto, restrição, no sentido de que as fundações, como as empresas públicas, procurem fins lucrativos, impostos à sua atividade no ato de instituição.

No entendimento moderno, sem qualquer base material de sustentação econômica, irrealizáveis são as fundações e as empresas públicas. É assim que, entre nós, o Estado tem criado várias fundações e empresas doando-lhes bens com destinação e fins previamente determinados.

Ultrapassada está a idéia de que as fundações só possam ter fins de utilidade particular. Superados estão as teorias que só admitem fins de utilidade particular para as empresas estatais. Aqui, no caso em debate, a propriedade coletiva, ou pública, é eminentemente instifucional, ou seja, voltada para a realização de certos fins públicos.

O sujeito do direito à propriedade coletiva, ou pública, é o Estado, sob a forma de uma pessoa jurídica constituída com firs de interesse público afetos à Administração. Manifesta a vontade do Estado não há como não admiti-la na sua expressão de força na ordem institucional. Vale, portanto, 0 ato de instifuição, o significado do ato criador.

Aqui fica bastante claro: a função que o Estado exercita através das fundações e das empresas públicas, escolhendo os meios de procedimento mais adequados, é uma função de intervenção. Intervenção pela qual a Administração se faz presente na extensão das suas prerrogativas e propósitos, ou como prestadora de serviços tanto sociais como econômicos.

\section{$18 .^{\circ}$ - INTERVENÇÃO E ATIVIDADE ADMINISTRATIVA}

Seria o caso de admitir a Administração agindo conforme impõe o princípio da especialidade. Intervindo em relações jurídicas de direito privado, embora mantendo as suas prerrogativas essenciais. Definindo de acordo com a lei a sua própria conduta e dispondo dos 
meios necessários para impor a respeito dessa conduta e para traçar a conduta alheia naquilo que com ela tenha relação. ( ${ }^{35}$ )

CAIO TÁCITO, informando que a tônica dos regimes políticos passou da abstenção para a intervenção, estabelece algumas valiosas premissas:

a) as Constifuições se enriquecem com novos direitos econômicos e sociais, tão relevantes para o homem comum como os seus direitos individuais e políticos;

b) o centro de gravidade da ordem jurídica se desloca, progressivamente, do individual para o social;

c) a intervenção do Estado no domínio econômico, que é uma constante do Direito Público contemporâneo, se definne ora sob forma programática, ora como norma legislativa, ora ainda, como uma atividade administrativa;

e) o Estado é, atualmente, um prestador de serviços tanto sociais como econômicos;

f) a atividade empresarial do Estado pode chegar, sob inspiraç̃̃es variadas, ao monopólio estatal;

g) característica, também do intervencionismo, é o planejamento econômico, tanto do setor público como do privado;

h) a propriedade, a família, o trabalho, a empresa passam a cbedecer, a novos pressupostos de interesse coletivo;

i) a liberdade e sobrevivência do indivíduo, a proteção contra os riscos sociais, a garantia de propriedade, da atividade profissional, do comércio e da indústria, se colocam a um tempo sob a proteção e a disciplina do Estado, numa escala que vai da ampliação do poder de polícia às formas mais amplas de socialização da economia. $\left({ }^{36}\right)$

Esse clima reformista do direito moderno, não leva como espera CAIO TÁCITO à instabilidade das instituições jurídicas tradicionais mas tão somente à procura de novas leis e códigos melhor adequados à atuação estatal no que diz respeito com o equilíbrio indispensável à consecução da segurança social e econômica. ( ${ }^{37}$ )

Tanto nas empresas personificadas, como nas fundações com personalidade jurídica privada, ambas as pessoas jurídicas com capital público, os matizes não se diferenciam na evolução histórica, nem na

35) André Gonçalves Pereira - ERRO E ILEGALIDADE NO ACTO ADMINISTRATIVO - ps. $34 /$.

36) Ver O DESAFIO DO ENSINO DE DIREITO - Carta Mensal do C.T.C.N.C. - Abril de 1971 - pg. 59/66.

37) Caio Tácito - trab. cit. - loc. cit. - p. 61. 
sua expressão mais moderna ou de clima reformisła, quanto à atividade do fim e de forma no que diz com a Administração indireta. ${ }^{(38)}$

Convém, porém, ressaltar que não mais existe hoje, aquela tendência à nacionalização dos serviços públicos que impressionou o espírito jurídico depois da última guerra na decada de 1950, provocando de VEDEL uma atitude radical em favor da politização e em oposição à fase liberal já ultrapassada na sua fisionomia histórica. $\left({ }^{(39)}\right.$

VEDEL largou àquele tempo a expressão que se fez famosa de que o Estado expropriou ou estava expropriando do capitalismo ou dos capitalistas não só suas empresas, como senão também suas experiências e suas fórmulas jurídicas com a intervenção e a adoção de formas societárias mercantís constituídas de capital público. ${ }^{\left({ }^{40}\right)}$

Mas o assombro com a expressão famosa não durou muito, pois - fenômeno nacionalizador haveria de dar lugar ao fenômeno do planejamento com a proliferação de entes de gestão econômica e social, capazes pela via da descentralização administrativa, de atender certos propósitos dentro da estrutura organizacional pública.

A evolução do pensamento jurídico se baseou na necessidade do desenvolvimento econômico e que é político, com a aceitação da presença indispensável do Estado na atividade econômica através de um processo racionalizador que ante a variedade de pessoas casuisticamente criadas, obrigou a Administração à optar por um regime racional e próprio de cunho eminentemente planejado e de caráter institucional.

Quanto à experiência generalizou-se em todos os países ociden tais de maior desenvolvimento, impondo a necessidade de uma reorde. nação jurídica assentada nos elementos surgidos da técnịca planificada aplicada à organização administrativa, adequadamente sujeita essa técnica às condições de forma, conteúdo e regime jurídico.

38) Destacam-se, na apreciação do fenômeno jurídico, face à capacidade interventora do Estado, alguns trabalhos de invulgar mérito prático e doutrinário, como: Aurelio Guvita - DERECHO ADMINISTRATIVO ESPECIAL - Vol. III - Zaragoza, 1967; Alfonso Perez Moreno - LA FORMA JURÍDICA DE LAS EMPRESAS PÚBLICAS - Sevilla, 1969; F. Garrido Falla - LA DESCENTRALIZACIÓN ADMINISTRATIVA - Costa Rica, 1967; Ernest Fersthoff - TRATADO DE DERECHO ADMINISTRATIVO - Madrid, 1959; Garcia - Trevijano TRATADO DE DERECHO ADMINISTRATIVO - Vol. II - Madrid, 1967; A. Buttgenbach THÉORIE GÉNÉRALE DE MODES DE GESTION DES SERVICES PUBLICS EN BELGIQUE Bruselas, 1952; Urbano Valero Agundez - LA FUNDACION COMO FORMA DE EMPRESA - Valladolid, 1969.

39) Ver LA TECNIQUe DES NATIONALISATIONS - Paris, 1946.

40) Georges Vedel - ob. cit. - DROIT SOCIAL - p. 93. 


\section{9. - A SIGNIFICAÇÃO DA FORMA JURÍDICA}

O caráter econômico, técnico ou de processo, estão no presente vinculando muito mais o Direito Administrativo à Ciência da Administração: importa considerar na descentralização como regime, dois fenômenos que exigem dimensionamento ajustado em planos que se equivalem na ordem decrescente hierárquica e funcional.

No primeiro dos fenômenos está a organização, mediante a qual a realidade estatal se projeta na realidade política de si mesma, isto é, ordenando formalmente a atividade administrativa instrumental nas diferentes esferas de comportamento público, harmonizando o sistema político. $\left.{ }^{41}\right)$

No segundo dos fenômenos estão as estrułuras através e mediante as quais a Administração efetiva a sua atividade de gestão, alargando o quanto possível a sua capacidade funcional, gerando órgãos, pessoas ou entes, que pela definição de competência e de objetivos, respondem à obrigatória ação estatal em diferentes esferas.

Daí porque, órgãos, pessoas ou entes, exigem forma jurídica cuja significação está no sentido da coordenação à organização adminıstrativa, ou seja à organização do Estado, forma jurídica que não se articula senão dentro do regime e da ordem jurídica instituída em razão do que oferece o direito vigente nas suas reais manifestações. $\left({ }^{42}\right)$

Compreende-se, portanto, o surgimento das fundações e empresas públicas como participantes da ordem jurídica estatal, sob forma clássicas mas adequadas às exigências do serviço público, criadas dentro do âmbito do ius publicum com o objetivo de alcance politico e não só patrimonial, instituidas em diferentes níveis e graus com personalidade jurídica, natureza própria e forma jurídica peculiar aos entes autonômos privados.

Ainda aqui, merece lembrança, a lição de PEREZ MORENO, que

41) Não cabe aqui, necessariamente, o exame do Estado na sua formação política. Numa visão mais ampla, não há como não atender, pelas suas implicações de regime e de ordem política, o Estado como corpo político. Basta dizer que o sistema jurídico é condição da organização estatal ou do Estado politicamente organizado. Sendo ele, ○ Estado, federal, apresenta-se em caráter de maior complexidade. E, sempre, por essência, composto, como soma de valores políticos que se integram num mesmo único poder, no caso brasileiro, a União Federal. Por sua vez, a União, não se realiza sem a participação, las unidades federadas. Nos Estados unitários já a organização política não exige maiores dimensōes. Nele, no Estado unitário, não prevalecem pressupostos que imponham a divisão do poder político, e, por consequência, a Administração não sofre divisōes cu repartiçöes na estrutura.

42) "En todo caso los problemas a resolver serán el Derecho aplicable a estes entes autónomos, cómo se relacionan con la Administración, y el valor de la atribución de personalidad jurídica en las relaciones con terceros" (Perez Moreno - ob. cit. - p. 66). 
se torna válida desde quando visualiza o problema em têrmos genéricos, para afirmar:

a) la Administración tiene un hambre de nuevas formas que sólo el Derecho comum ha habido y podido suministrarle;

b) junto a la decantada politización del Derecho comum cabia colocar la privatización del Derecho público, no en cuanto a su sustancia especifica, ya que la Administración, aun cuando actuando bajo régimen privatistico, no pierde jamás su carácter de "públicas potestas", sine en cuanto a la forma jurídica a que se semeten las nuevas tarefas administrativas. $\left({ }^{43}\right)$

Sem dúvida, não há como contrariar a Administração, ou o poder administrativo, ou o Estado, não admitindo a plena compatibilidade entre a organização do ente segundo a estrutura jurídica mais adequada a seus fins, tendo em conta o caráter instrumental e de processo que interesse à Administração no uso das suas prerrogativas.

Sabe hoje a doutrina, que o chamado regime privatistico, não é estranho à Administração quando expressa a sua vontade pública ou política. Nas pessoas jurídicas fundacionais efetivamente o poder público procura a descentralização funcional ou a descentralização por serviços. Nas empresas, ou através delas, o que o Estado procura, é dinamizar um objetivo econômico no plano onde possam preponderar elementos jurídicos combinados de regime jurídico, e que melhor disciplinem a forma jurídica.

Certamente, a doutrina, por imposição de certas posições doutrinárias, não se mostra unânime quanto à forma das fundações e das empresas públicas. $O$ processo, porém, deve caber o Estado, dentro do princípio da unidade administrativa. A obrigação do respeito à legalidade não impede a escolha do regime mais adequado. Tendo em mira fatores condicionantes que dão configuração a tipos de pessoas, tanto pode o Estado adotar a forma pública, ou a privada, se esta lhe parecer a mais conveniente.

Acresce, sobretudo, reconhecer, que a característica dos entes fundacionais com forma jurídica de empresa pública está na personalidade jurídico-pública, mas com submissão da sua atividade ao direito privado, especialmente quando o Estado no ato criador define - tipo da pessoa na relação jurídica e diante dos objetivos a alcançar. Assim afirma o Estado, como instituidor e organizador, a sija capacidade de Direito Administrativo. Capacidade que não ampara as funda. ções privadas.

43) Ver LA FORMA JURÍDICA... - ob. cit. - p. 76. 
Preponderam três elementos fundamentais no sentido da caracterização da forma jurídica:

a) o elemento vontade fundadora do Estado;

b) o elemento patrimonial para consecução de um fim;

c) o elemento organização para cumprimento desse fim com a fixação de meios pessoais e materiais necessários.

A modalidade de ente fundacional, com forma de empresa pública, supõe reconhecimento de finalidade que pela atividade pretendem a gestão de serviços públicos econômicos. A forma jurídica, por consequência, responde a uma necessidade, ou a necessidade que se manifestam na esfera própria de responsabilidade da Administração. A colaboração de pessoas privadas na gestão administrativa pública tornou-se num fato natural e numa solução normal do nosso tempo, dado o sentido organizador de Direito Administrativo. ${ }^{(44}$ )

\section{$200^{\circ}-$ CONCLUSÃO}

Enquadram-se, teórica e praticamente, as conclusões que expontaneamente aparecem dos fatos que envolvem a condição administrativa, nos seguintes itens cuja importância indicam a capacidade generalizadora do Estado, no tocante aos serviços públicos que envolvem a plena responsabilidade da Administração:

a) somente pela descentralização funcional e de serviços pode a Administração arcar com as exigências de ordem administrativa, so. cial, econômica e assistencial, que fazem fim para o Estado dentro das suas prerrogativas políticas;

b) essa descentralização caracteriza-se no sentido dinâmico pela transferência de funções ou competências da Administração às demais pessoas jurídicas públicas ou privadas e para atender condições territoriais e institucionais;

c) o nexo causal e jurídico entre os entes funcionalmente descentralizados e o Estado impõe a tutela face à natureza da relação, dependência hierárquica, a forma personificada e a forma jurídica adotada;

d) a posição do Estado é a mesma quanto às fundações e às empresas públicas desde o momento em que as enquadra na organização estatal por constituição coativa;

e) tanto as fundações como as empresas organizadas em forma

44) Em parte é essa a orientação de Perez Moreno quando ressalta a importância das relaçōes de cooperação sobre as relações de estrita subordinação - ob. cit. - p. 266. 
de serviço público no sentido geral são fenômenos típicos de descentralização administrativa assumindo a personalidade melhor condizente com o fim esperado;

f) considerando a relação de hierarquia e a relação de tutela o regime jurídico será sempre aquele que o Estado preferir para todos os entes inferiores que participam ou passem a participar da Administração indireta;

g) na realidade nada há que impeça o Estado de criar fundações com forma de empresa destacando no ente autonômo personificado o regime conveniente, e isso em razão da natureza da atividade que pretende exercitar.

h) mostra-se a vontade estatal através de substratum personificado que dá vida ao ato de criação em cada caso para tudo quanto disser respeito à forma concreta, à estrutura jurídica peculiar e organizacional administrativa.

Adotamos aqui, sem reservas, a tese de VALERO AGUNDEZ:

- "el fundador puede estab!ecer en el negocio fundacional las normas, conforme a las cuales deben estructurarse y actuar los órganos de la fundación". $\left({ }^{45}\right)$

Com o fato, as empresas fundacionais privadas, em nada se conflitam substancialmente com a natureza histórica da instituição. A эção do Estado, pela vontade, é a mesma. A necessidade de controle rambém igual na fundação - empresa.

Quanto ao controle no funcionamento da empresa fundacional será o problema apenas estatutário, pois, em princípio, resultando da intervenção de órgãos públicos ou da Administração, a função de poder outorgada pelo fundador, limita-se às regras ou disposições que garantam o cumprimento da vontade nascida do ato de instituição.

Paralelo às tradicionais formas de empresa a nova forma de fundação, com peculiaridades econômicas no setor privado ou público, dificuldade maior não oferece no tocante ao conceito, possibilidade e regime jurídico. Ressalte-se, fundamentalmetne, como essencial, a vontade do fundador, em torno da idéia central, que o levou à criação do ente.

Como nas fundações, pessoas criadas de direito positivo, no fim está precisamente o seu objetivo. A figura típica, histórica, clássica das

45) Ver LA FUNDACION - ob. cit. - p. 314. 
fundações, já não basła na atualidade. As exigências do interesse público de tal maneira aumentaram que estão a exigir do Estado ação mais eficiente e disciplinadora. Ação instrumental que se ampare nos elementos coadjuvantes que the oferece o direito privado.

No sistema do Código Civil, apesar dos preceitos unitários aplicáveis, não se diz ao certo o que seja o interesse ou a necessidades públicas. Em consequência, o interesse público, ou a necessidade, con verte-se em algo não tipificado nos dias ałuais, para o direito moderno na sua expansão socializadora.

Mas há uma verdade, em que a doutrina é bastante segura: todos os ordenamentos jurídicos que admitem a figura da fundação outorgam sua proteção à vontade do fundador, para garantir não só - cumprimento das suas finalidades, mas para reconhecer na vontade do fundador a norma suprema da fundação. $\left({ }^{46}\right)$

Fora de tal verdade, não existe outro caminho para a Administração, em consonância com a ordem jurídica institucional. Está certo que o fim objetivado pelas fundações venha claramente marcado bela condição de inalterabilidade. Mas a inalterabilidade desse fim não é nunca absoluta. Seria gravemente prejudicial para a fundação se assim - fosse. As circunstâncias que mudam podem obrigar necessariamente à novas adaptações, sem quebra de fidelidade à vontade do fundador ao constituir a fundação. ${ }^{47}$ )

Não há, portanto, um critério rigorosamente exato, quanto à evolução do fim e o caráter permanente das fundações. Não havendo um critério exato, permite-se às fundações em razão do ordenamento jurí. dico, que assumam em qualquer tempo ou no momento da criação, finalidades que melhor digam com a pretensão do Estado sempre sensível a fatos essenciais novos que buscam racional entendimento e formulação. ${ }^{48}$ )

Justificando-se a fundação emprèsa, no Estado moderno pressionado por tantas exigências, ainda vale sobretudo o princípio tradicional que reconheço a vontade do instituidor como a lei que rege a fundação. Para tipificar a fundação, com forma de empresa, basta a presença do fim de atividade empresarial, conforme as diretrizes impostas pelo fundador no ato de criaç̧ão. A adequação à atividade ezconômica ordenada estatutariamente reflete elementos definidos com titularidade jurídica imediata.

46) Valero Agundez - ob. cit. - p. 28.

47) Urbano Valero Agundez - ob. cit. ps. 31/33.

48) Carácter de las normas del Derecho de la fundación - Agundez - ob. cit. ps. 64/5. 